\title{
DEBATES
}

\section{Para quem a internet é central no Brasil? Uma medida de centralidade da internet e dos usuários a partir da Pesquisa Brasileira de Mídia}

\author{
For who is internet central in Brasil? A centrality measure of the \\ internet and users' profile from the "Pesquisa Brasileira de Midia"
}

\section{Emerson Urizzi Cervi}

\section{Resumo}

O artigo tem o objetivo de descrever quem é o usuário de internet no Brasil, a partir de uma pesquisa com amostra nacional de 18 mil respondentes em 2014. Com isso, é possível identificar nuances e características específicas dos usuários de internet por características socioeconômicas individuais, como renda, idade, escolaridade e também por características macrossociais, como região do país e tipo de município em que vive o usuário. A hipótese é que, a exemplo do que acontece em outros países, os limites econômicos não são mais barreiras significativas para o não uso da internet. Aqueles que não usam internet o fazem por opçáo e não por limitação econômica. As diferenças seriam explicadas por outras características, como escolaridade e idade. Para testar a hipótese, construímos o Índice de Centralidade da Internet e comparamos os perfis socioeconômicos e geoGráficos a partir da posição no índice. Os resultados mostram um deslocamento parcial da TV para a internet.

\section{Palavras-chave}

Survey; Opinião Pública; Internet; Brasil; Índice de Centralidade.

\begin{abstract}
The article aims to describe who is the internet user in Brazil, based on a national sample survey with 18,000 respondents in 2014. It's possible to identify specific nuances and characteristics of internet users by individual socio-economic characteristics, such as income, age, education, and also macrosocial features, such as the region of the country where the user lives. The hypothesis is that similarly to what happens in other countries, the economic limits are no longer significant barriers for not using the internet. Those who do not use the internet do so by choice and not by economic limitations. The differences would be explained by other characteristics, such as education and age. To test the hypothesis we have built the Internet Centrality Index and we have compared the socioeconomic and the geographic profiles by the position in the index. The results show a partial shift from TV to the internet.
\end{abstract}

\section{Keywords}

Survey; Public Opinion; Internet; Brazil; Centrality Index. 


\section{Introdução ${ }^{1}$}

$\mathrm{O}$ artigo insere-se na discussáo sobre sociedade e internet, tipos de usos da internet, comportamento do usuário e as diferentes finalidades dadas por ele aos meios de comunicação em rede. Mais especificamente, aborda um aspecto dessa discussão, pouco explorado até aqui pela literatura da área, que é a identificação do usuário da internet a partir de respostas a surveys - e náo em função do tipo de uso e interação na internet ${ }^{2}$. Sabe-se que algumas características isoladas, tais como ser jovem e viver em cidades integrantes de regiôes metropolitanas, ajudam a caracterizar o usuário de internet no Brasil. No entanto, não há uma identificação mais detalhada de quem é esse usuário e, também, do que delimita os diferentes níveis de utilização da rede mundial de computadores.

Pretende-se, a partir dos dados disponíveis na Pesquisa Brasileira de Mídia 2014³ , sob responsabilidade da Secretaria de Comunicação do Governo Federal (BRASIL, 2013), cumprir dois objetivos principais: identificar qual o grau de importância que o brasileiro dá para a internet em comparação a outros meios de comunicação e, em segundo lugar, propor um índice que seja capaz de medir os diferentes níveis de relevância que as pessoas dão para a internet. De forma complementar, uma vez definida a relevância, será possível cruzar com informaçôes socioeconômicas e geoGráficas disponíveis no survey para caracterizar o usuário de internet por nível de centralidade.

Para cumprir os objetivos, propóe-se o Índice de Centralidade da Internet $(\mathrm{ICI})^{4}$ para o brasileiro. A partir de respostas ao survey, este índice pretende classificar

${ }^{1} \mathrm{O}$ autor agradece as contribuiçôes feitas pelos pareceristas e revisores da Revista.

${ }^{2}$ Versão preliminar do artigo foi apresentada no Congresso da Word Association Public Opinion Research (Wapor) sobre "Opinión Publica, Crisis de Representación y Nuevas Formas de Participación", em Santiago - Chile, 2014.

${ }^{3} \mathrm{O}$ survey é uma amostra representativa da população brasileira acima de 16 anos, sendo possível extrair amostras representativas para cada região do país. A amostra total é composta por 18.312 entrevistas, com margem de erro máxima estimada de um ponto percentual e intervalo de confiança de 95\%. A amostra foi estratificada por região do país, municípios, setor censitário e por cotas proporcionais a sexo, idade, grau de instrução e ramo de atividade. As entrevistas face a face foram realizadas entre 12 de outubro e 6 de novembro de 2013, a partir de um projeto da Secretaria de Comunicação (Secom) do Governo Federal. O trabalho de campo e de modelagem do banco de dados foi realizado por Ibope-Inteligência.

${ }^{4}$ A construção de índices de centralidade é comum em pesquisas que têm por objetivo identificar níveis de relevância de determinada característica/objeto para uma populaçáo qualquer. É usado em diferentes áreas. Pereira et al. (2011) propóem um índice de centralidade urbana para comparar níveis de desenvolvimento social entre países. Aqui, o Índice de Centralidade da Internet visa distinguir os usuários que buscam informaçóes na internet daqueles que o fazem em outros meios de comunicação. 
os respondentes em dois níveis. Primeiro, entre os que consideram a internet como um meio de comunicaçáo importante para o seu cotidiano e aqueles que consideram mais relevantes outros meios (TV, rádio, jornais, revistas e outros). Em segundo lugar, entre os que dizem que a internet tem alguma centralidade como meio de comunicação, estabelecer níveis que vão da menor para a maior centralidade. Feito isso, será possível identificar que características socioeconômicas e geoGráficas ajudam a definir o brasileiro que considera a internet um meio de comunicação central em seu cotidiano.

A Pesquisa Brasileira de Mídia (PBM) apresenta quatro baterias de questóes que podem compor o ICI. Duas delas são externas à internet, pois a comparam a outros meios. Uma fornece informaçôes sobre que meios (em ordem decrescente de importância) o cidadáo mais usa. Outra pergunta identifica que meios (também em ordem decrescente de importância) o cidadão mais usa para se informar a respeito do país. A essas duas, são reunidas outras de caráter interno, ou seja, sobre o uso específico da internet, e que ajudam a compor a centralidade desse meio para a comunicação dos cidadãos. Uma identifica quanto tempo em média (número de horas) o respondente costuma navegar na internet diariamente. A última aborda uma dimensão qualitativa e informa qual o grau de confiança que o cidadão tem nas informaçôes que recebe de diferentes fontes da internet. A hipótese é que para pessoas que dão à internet grande centralidade, o meio é citado entre os de maior uso, é onde elas mais buscam informaçóes sobre o Brasil, tendem a navegar acima da média geral de horas diárias e confiam bastante nas informaçóes que recebem desse meio.

Outra questão visa identificar que variáveis socioeconômicas e geoGráficas são mais fortes para a explicação das variaçôes de centralidade da internet para o brasileiro médio. Espera-se que variáveis individuais, tais como sexo, escolaridade, renda e idade, sejam mais importantes para a caracterização da centralidade da internet do que as variáveis agregadas: regiáo do país, tamanho do município e tipo de município 5 .

A forma como as pesquisas sobre internet e sociedades modernas tem se desenvolvido explora preferencialmente outros aspectos dessa relação que não as características dos usuários. Uma das primeiras abordagens a se consolidar nesse campo foi a que tratava a internet como uma ferramenta de transformaçáo das

Com isso é possível comparar características socioeconômicas de quem a internet é central em relação aos demais.

${ }^{5}$ Uma possibilidade de refinar ainda mais a análise seria acrescentar variáveis identificadoras de dados socioeconômicos agregados por município, como IDH ou o índice de satisfação do usuário de telefonia, medido pela Anatel. No entanto, isso não é objeto do atual trabalho. 
práticas políticas e interaçóes sociais em geral. Nesse campo encontram-se as pesquisas de Bucy e Gregson (2000), Papacharissi (2004), Castells (2009) e Pogrebisnchi (2012), entre outros. Antes de discutir quem era o usuário de internet, esses autores preocupavam-se em explicar como um meio de comunicação em rede transformaria as formas de atuação no espaço público. Um segundo conjunto de pesquisas, em complemento à anterior, foca atenção na maneira como as elites políticas podem utilizar a internet para legitimar suas açôes (MAIA, 2011; CERVI, 2012; MARQUES, 2012; MCKEEVER e RAPPORT, 2012) ou a forma como a internet pode ser usada em campanhas eleitorais (IASUILATIS, 2012; FUENTES, 2012). Também existem abordagens específicas sobre como a internet transforma as maneiras de acessar conteúdos jornalísticos, redimensionando a esfera pública (DAHLGREN e SPARKS, 1993). Uma das definições mais produtivas para a importância da internet na comunicação política é de Tedesco (2004), na qual reforça a posiçáo de outros autores de que a internet seria um meio de comunicação central (master medium), pois seria um híbrido entre os meios unidirecionais impressos e audiovisuais de massa que oferece a oportunidade de uma comunicaçáo nos dois sentidos, oferecendo feedback permanente. Além disso, a internet seria revolucionária porque nela reduz-se o controle sobre a seleção das informaçóes, o que caracteriza os meios tradicionais impressos ou eletrônicos.

Em todos os casos citados anteriormente, os estudos não consideram a caracterização do usuário da internet como central para as pesquisas. Um dos poucos trabalhos recentes que trata do perfil do usuário da internet é o de Lazer et al. (2010) ao descrever uma relaçáo temporal entre o desenvolvimento das redes de comunicação e mudanças nas atitudes políticas. Com uma abordagem distinta, Lomborg (2012) mostra como as redes sociais exercem pressóes sobre as açóes dos usuários - nesse caso, especificamente analisando as redes de usuários do twitter. De qualquer maneira, o perfil dos usuários também não é objeto central do trabalho desses autores. Nesse sentido, destaca-se o trabalho de Echegaray (2002) que faz uma das primeiras descriçôes do perfil do usuário de internet no Brasil, considerando a segmentaçáo social como preditor para padróes de consumo e de manifestação política na internet.

Com o objetivo de caracterizar o usuário de internet no Brasil, para produzir o ICI usamos um conjunto de técnicas e testes específicos na formulação de índices a partir de respostas a perguntas de surveys. Começamos com a proposta de teste da confiabilidade das variáveis apresentada por Cronbach (1951) e detalhado por Cortina (1993). Também usamos as justificativas de Carmines e Zeller (1979) para os testes de confiabilidade de índices. Em seguida, aplicamos a técnica de regressão 
binária (ELLIOT, 2008) para verificar que características socioeconômicas e geoGráficas dos respondentes estáo mais fortemente associadas à centralidade da internet no cotidiano dos cidadãos. Por fim, utilizamos a técnica de análise de resíduos padronizados para identificar que categorias de cada variável socioeconômica apresentam relaçóes mais fortes com centralidade de uso da internet.

Após a criação do Índice ICI é possível identificar diferenças socioeconômicas entre os que consideram a internet central para obtenção de informaçóes dos que não usam o meio. Para fins introdutórios, as respostas obtidas no survey da PBM foram organizadas em forma de um Gráfico de redes, com a única finalidade de representar as formas de distribuiçáo das respostas em relação ao uso dos meios de comunicação. Não se fará aqui a utilização de técnicas de análise de redes, o que exigiria uma discussão que iria muito além de uma introdução. $\mathrm{O}$ Gráfico de redes ${ }^{6}$ a seguir (Gráfico 1) representa a distribuição dos meios de comunicação para se informar (Gráfico 1.1) e os que consideram a internet central para a busca de informaçóes (1.2). Percebe-se que o ICI é capaz de representar o fenômeno estudado aqui, pois ele coloca a internet na posição mais central da rede no Gráfico 1.2. Já para os que não consideram a internet entre os principais meios de comunicação, a TV aparece como central. Ao final do trabalho espera-se distinguir as características dos respondentes do survey que compóem o Gráfico 1.1 e o Gráfico 1.2.

${ }^{6}$ Para mais detalhes sobre a análise de redes a partir de NodeXL, ver Smith et al., 2009. 
Gráfico 1 - Redes para os que não citam internet e para os que a consideram central

\begin{tabular}{l|l|}
\hline \\
1.1 Internet sem centralidade para o entrevistado
\end{tabular}

Fonte: Autor, a partir da Pesquisa Brasileira de Mídia 2014 (BRASIL, 2013).

Dos entrevistados no survey, 10.249 não citam internet como um dos principais meios acessados. Outros 8.063 fazem parte do grupo para os quais a internet apresenta algum nível de centralidade entre os meios de comunicação. A técnica de análise de redes por formação de clusters identifica dois clusters em cada um dos grupos. No primeiro (1.1), há um cluster formado pelos meios de comunicação tradicionais (TV, rádio, revistas e jornal) e outro cluster formado por outros meios não midiatizados (conversa com amigos, panfletos, etc.) - são os nós não identificados no Gráfico por apresentarem baixo número de ocorrências. A divisão em clusters mostra a existência de tendência de repetição das respostas entre os integrantes de cada um dos grupos. No segundo grupo, dos que consideram internet com alguma centralidade, também existem dois clusters, porém, com uma diferença significativa. No cluster 1, estão Internet, Rádio, Jornais e Revistas. No 
cluster 2, encontram-se TV, panfletos, conversa com amigos e outros. Isso pode ser interpretado como uma replicaçáo do uso da internet com o demais meios, exceto a TV, que passa a ser citada pelos entrevistados que náo usam os demais veículos de comunicaçáo tradicionais. Ou seja, a TV estaria presente em todos os grupos, entre os que usam ou não internet ${ }^{7}$.

A partir daqui o texto está dividido em três partes. $\mathrm{Na}$ próxima são apresentadas as frequências simples das respostas a cada uma das baterias de perguntas do survey. Em seguida as variáveis são testadas para verificar a consistência interna dos componentes do ICI. Uma vez definida a composição do índice, no tópico seguinte ele será cruzado com as variáveis socioeconômicas e geoGráficas apresentadas pela pesquisa. O objetivo dos cruzamentos é identificar que características são mais importantes para identificar o perfil do usuário de internet no Brasil. Por fim, são apresentadas as notas conclusivas do artigo.

\section{Itens do Índice de Centralidade da Internet}

$\mathrm{O}$ índice proposto aqui é composto por quatro variáveis que representam duas dimensôes distintas da relação do usuário com a internet. A primeira dimensão é chamada de "externa" e indica o grau de centralidade da internet para o respondente em relação aos demais meios de comunicação. Esta dimensão serve para identificar quem são os respondentes que dizem usar mais a internet em comparação a outros meios de comunicaçáo. A segunda dimensão é "interna" e serve para classificar os que dizem preferir internet a outros meios em volume de uso (por horas diárias) e grau de confiança nas diferentes modalidades de transmissão de informaçôes pela internet (sites, blogs e redes sociais).

\footnotetext{
${ }^{7}$ Duas estatísticas para análises de redes são apresentadas no Gráfico 1, com objetivos complementares. A primeira é a média da distância geodésica, que é o resultado da soma dos menores pares de vértices divididos pelo número possível de pares de vértices. Quanto menor o valor, mais próximos são os limites, ou seja, mais "próximos" são os pontos da rede em média. A rede sem internet apresenta média de 1,020 e com internet, 1,234. O que significa que há uma homogeneidade maior nas distâncias entre os meios de comunicação sem internet do que com a internet. Outra estatística apresentada para mostrar diferenças entre as redes é a densidade do Gráfico. A densidade é calculada levando em consideração o número real de limites e o número máximo. Quanto maior o número, mais denso é o Gráfico. No Gráfico 1.1 a densidade é de 0,001 e no Gráfico 1.2 fica em 0,611, o que significa que, para os que citam internet, a rede é mais densa, indicando uma maior proximidade entre os limites individuais e entre os clusters. Já para os que não citam a internet, a rede é mais esparsa. Em resumo, para os que não citam internet, a distribuição do uso dos demais meios é mais homogênea e a rede é mais esparsa. Já para o grupo que cita internet, percebe-se maior heterogeneidade, com meios mais próximos entre si, deixando a rede mais densa (Gráf. 1.2).
} 
O questionário aplicado apresenta quatro conjuntos de perguntas que interessam para a montagem do índice que medirá o grau de interaçáo via internet do cidadão brasileiro. O primeiro, formado por três perguntas (P101, P102 e P103) questiona qual o meio que o respondente mais usa. As alternativas são: TV, rádio, jornal, revista, internet, panfletos, conversa com amigos e outros. Para a primeira pergunta a resposta refere-se a qual meio está em primeiro lugar em uso. A segunda pergunta repete todas as alternativas e procura saber qual está em segundo lugar. E a terceira pergunta indaga qual dos meios está em terceiro lugar em uso para o respondente. Estas perguntas claramente indicam qual a importância geral que o respondente dá para cada um dos meios.

A segunda bateria de perguntas usada na composição do índice (P201, P202) indaga em qual dos meios citados o respondente mais se informa sobre o que acontece no Brasil. No caso, a primeira questão procura saber qual é o meio que mais usa. A segunda, qual o meio em que mais busca de informaçóes sobre o Brasil. Essas duas baterias de perguntas cumprem um duplo papel na identificação do usuário de internet. O primeiro é distinguir os que respondem "internet" dos demais meios. Como pretendemos criar um índice para ser usado na identificação do perfil do usuário da internet no Brasil, separamos os que dizem ser usuários da internet dos demais. Em seguida, fazemos a gradação de intensidade no uso da internet. Quem responde que "internet" é o meio que mais usa na questáo P101, significa que é um usuário mais intenso do que quem responde "internet" na P102, que indica o segundo meio que mais usa e assim sucessivamente. O mesmo se aplica à P201. Se o respondente diz que se informa principalmente pela internet, esse meio tem mais intensidade na busca de informaçôes do que para as respostas na questáo seguinte, que é "internet" em segundo lugar para se informar sobre o Brasil.

A terceira bateria de perguntas usada no índice é específica para o volume de uso da internet. O questionário apresenta duas perguntas (P3398, P3501) para medir o número de horas de uso de internet em média por dia. A primeira pergunta indica a média de horas diárias de uso da internet entre segunda-feira e sexta-feira. A segunda mede o número de horas de navegação na internet nos finais de semana.

A quarta e última bateria de perguntas usada na construção do índice diz respeito à confiança que o usuário de internet tem nas informaçóes que circulam nesse meio. As perguntas (P6015, P6106, P6107) oferecem como alternativas de respostas válidas: "confia sempre”, "confia muitas vezes", "confia poucas vezes", "nunca confia" para as modalidades de notícias em sites, blogs e redes sociais, respectivamente. A hipótese aqui é a de que os usuários mais intensos, aqueles que indicam usar internet por mais horas, consumir mais informação pela internet e ter 
mais horas de navegação por dia em média tendem a, também, apresentar maiores níveis de confiança nas informações que circulam nesse meio. As quatro baterias de questôes são agrupadas e transformadas para o processo de composição do índice, conforme resumido no Quadro a seguir:

Quadro 1 - Sumarização dos itens integrantes do Índice de Centralidade da Internet

\begin{tabular}{|c|c|c|c|c|}
\hline Dimensáo & Variável & Questóes & Alternativas originais & Respostas transformadas \\
\hline \multirow[t]{2}{*}{$\begin{array}{l}\text { Externa: } \\
\text { comparação } \\
\text { entre internet } \\
\text { e outros } \\
\text { meios de } \\
\text { comunicação }\end{array}$} & $\begin{array}{l}\text { Qual o meio } \\
\text { que mais usa }\end{array}$ & $\begin{array}{l}\text { P101 } \\
\text { P102 } \\
\text { P103 }\end{array}$ & $\begin{array}{l}\text { 1-TV } \\
\text { 2-Rádio } \\
\text { 3-Jornal Impresso } \\
\text { 4-Revista impressa } \\
\text { 5-Internet } \\
\text { 11-Panfletos } \\
\text { 12-Conversa com amigos } \\
\text { 990-Outros/não válidas }\end{array}$ & $\begin{array}{l}\text { 1-Internet } \\
0 \text {-Demais respostas válidas } \\
\text { (para medir as diferenças } \\
\text { de intensidade, na primeira } \\
\text { questão o peso é } 3 \text {, na } \\
\text { segunda o peso é } 2 \text { e na } \\
\text { terceira, peso } 1 \text { ) }\end{array}$ \\
\hline & $\begin{array}{l}\text { Qual o meio } \\
\text { que mais se } \\
\text { informa } \\
\text { sobre o Brasil }\end{array}$ & $\begin{array}{l}\text { P201 } \\
\text { P202 }\end{array}$ & $\begin{array}{l}\text { 1-TV } \\
\text { 2-Rádio } \\
\text { 3-Jornal Impresso } \\
\text { 4-Revista impressa } \\
\text { 5-Internet } \\
\text { 11-Panfletos } \\
\text { 12-Conversa com amigos } \\
\text { 990-Outros/não válidas }\end{array}$ & $\begin{array}{l}\text { 1-Internet } \\
0 \text {-Demais respostas válidas } \\
\text { (para medir as diferenças } \\
\text { de intensidade, na primeira } \\
\text { questão o peso é } 2 \text { e na } \\
\text { segunda o peso é } 1 \text { ). }\end{array}$ \\
\hline \multirow{2}{*}{$\begin{array}{l}\text { Interna: } \\
\text { comparação } \\
\text { entre } \\
\text { intensidade e } \\
\text { valor dado à } \\
\text { internet pelos } \\
\text { usuários }\end{array}$} & $\begin{array}{l}\text { Quantas } \\
\text { horas de uso } \\
\text { de internet } \\
\text { por dia }\end{array}$ & $\begin{array}{l}\text { P3501 } \\
\text { P3698 }\end{array}$ & $\begin{array}{l}\text { Número de horas } \\
\text { completas por dia durante } \\
\text { a semana e nos finais de } \\
\text { semana. }\end{array}$ & $\begin{array}{l}\text { Média do número de horas } \\
\text { durante a semana e nos } \\
\text { finais de semana. }\end{array}$ \\
\hline & $\begin{array}{l}\text { Confiança } \\
\text { nas notícias } \\
\text { que circulam } \\
\text { na internet }\end{array}$ & $\begin{array}{l}\text { P6105 } \\
\text { P6106 } \\
\text { P6107 }\end{array}$ & $\begin{array}{l}\text { 1-Confia sempre } \\
\text { 2-Confia muitas vezes } \\
\text { 3-Confia poucas vezes } \\
\text { 4-Nunca confia } \\
\text { 91-Não se aplica/não } \\
\text { válidas }\end{array}$ & $\begin{array}{l}\text { Média dos valores de } \\
\text { confiança para as três } \\
\text { modalidades (sites, blogs e } \\
\text { redes sociais) invertida para } \\
\text { que maior confiança fique } \\
\text { com código mais alto. }\end{array}$ \\
\hline
\end{tabular}

Fonte: Pesquisa Brasileira de Mídia 2014 (BRASIL, 2013).

Antes de tratarmos da transformação das variáveis para composição do índice, apresentamos os resultados obtidos na pesquisa para cada uma delas, separadamente. A primeira questáo é sobre o uso dos meios de comunicação. A Tabela 1 a seguir mostra os resultados para as três perguntas, de primeiro a terceiro lugar, qual o meio que mais usa. O meio que interessa é "internet". Percebe-se que no total, 37,3\% dos 
respondentes (percentual total) disseram usar internet entre primeiro e terceiro lugar ${ }^{8}$. Outra informação importante é que o percentual de usuários de internet cresce na segunda opção, passando de 12,2\% em primeiro lugar para 16,5\% em segundo lugar. Porém, se considerarmos apenas os percentuais de respostas válidas para um dos meios de comunicação, a inclusão de "internet" entre uma das três posiçôes sobe para 69,8\%, com crescimento no percentual de escolha de "internet" para as últimas posiçôes na classificação. Há mais respostas para internet em terceiro lugar $(33,4 \%)$ do que em segundo lugar $(24,1 \%)$ e do que em primeiro lugar (12,3\%). A ordem de uso da internet é inversa à da TV. Enquanto esse último meio apresenta alto percentual como primeira opçáo $(77,9 \%)$, ele tem queda para as colocaçóes seguintes, enquanto a internet tem menor percentual como primeira opção e cresce na terceira opção. Embora ainda fique muito distante da TV, com praticamente $100 \%$ de citação entre primeiro e terceiro lugar, seria um equívoco considerar apenas a primeira citação de uso de internet, pois desconsideraria mais da metade dos respondentes que dizem usar a internet em segundo ou terceiro lugar. Se considerarmos apenas a primeira opção, encontraremos a internet como segundo meio que mais se usa, atrás apenas da TV. A última coluna da Tabela 1 mostra a soma dos três percentuais válidos para cada meio de comunicação. No caso da TV, a soma de $104,4 \%$ indica que respondentes optaram por TV em mais de uma das respostas dadas. Ou seja, na pesquisa alguns respondentes citaram a TV como primeira e terceira em uso, por exemplo, o que é válido para os casos em que a concentração de uso da TV é alta. Esse é o meio de maior uso no Brasil. Em segundo lugar, no acumulado, vem o Rádio, com $79,4 \%$ de total, concentrando-se principalmente como segundo meio mais usado. Em terceira colocação no acumulado vem a internet, com $69,8 \%$ do total e uma concentração de respostas no terceiro meio mais usado.

\footnotetext{
${ }^{8}$ A decisão de indicar os dois percentuais (total e válido) aqui se justifica em função das distintas informaçóes transmitidas por eles. O percentual total é baixo porque considera todos os respondentes da pesquisa, inclusive os que não deram respostas válidas para uma das três classificaçóes. $\mathrm{O}$ terceiro lugar, por exemplo, apresenta $74,1 \%$ de não respostas, o que mostra que os respondentes optaram principalmente por citar um ou dois meios de comunicação que usam. Para uma análise sobre a concentração de usos, o percentual total seria fundamental. Tanto que $99,4 \%$ têm respostas válidas para o $1^{\circ}$ lugar (total válido), 68,8\% em $2^{\circ}$ lugar e apenas $25,9 \%$ em $3^{\circ}$ lugar, indicando que apenas um em cada quatro respondentes indica o uso de um terceiro meio de comunicação. Já o percentual válido apresenta a distribuição das respostas entre os meios de comunicação apenas para os respondentes que apontaram usar três meios de comunicação. Para os fins de análise deste artigo, o percentual válido é o que interessa, pois estamos criando um ranking dos que dizem usar internet frente a outros meios.
} 
Tabela 1 - Repostas às questôes: "Vou apresentar uma lista de meios de comunicação e gostaria de saber qual o(a) senhor(a) usa mais?" por ordem de classificação

\begin{tabular}{|c|c|c|c|c|c|c|c|c|c|c|}
\hline \multirow{2}{*}{$\begin{array}{c}\text { Meios de } \\
\text { Comunicaçáo }\end{array}$} & \multicolumn{3}{|c|}{$1^{\circ}$ lugar } & \multicolumn{3}{|c|}{ 2o lugar } & \multicolumn{3}{|c|}{ 3o lugar } & \multirow{2}{*}{$\begin{array}{l}\text { Total } \\
\text { Soma } \\
\text { \%vál. }\end{array}$} \\
\hline & $\mathrm{N}$ & $\%$ & \%vál. & $\mathrm{N}$ & $\%$ & \%vál. & $\mathrm{N}$ & $\%$ & \%vál. & \\
\hline TV & 14.260 & 77,9 & 78,3 & 2.450 & 13,4 & 19,5 & 309 & 1,7 & 6,6 & 104,4 \\
\hline Rádio & 1.395 & 7,6 & 7,6 & 5.916 & 32,3 & 46,9 & 1.180 & 6,4 & 24,9 & 79,4 \\
\hline Jornal impresso & 218 & 1,2 & 1,2 & 951 & 5,2 & 7,6 & 1.224 & 6,7 & 25,8 & 34,6 \\
\hline $\begin{array}{l}\text { Revista } \\
\text { impressa }\end{array}$ & 43 & 0,2 & 0,2 & 248 & 1,4 & 1,9 & 441 & 2,4 & 9,3 & 11,4 \\
\hline Internet & 2.237 & 12,2 & 12,3 & 3.025 & 16,5 & 24,1 & 1.583 & 8,6 & 33,4 & 69,8 \\
\hline $\begin{array}{l}\text { Conversa com } \\
\text { amigos/ } \\
\text { parentes }\end{array}$ & 59 & 0,3 & 0,4 & 0 & 0,0 & 0,0 & 0 & 0,0 & 0,0 & 0,4 \\
\hline $\begin{array}{l}\text { Outros/Náo } \\
\text { Válido }\end{array}$ & 100 & 0,5 & & 5.722 & 31,2 & & 13.575 & 74,1 & & \\
\hline Total válido & 18.212 & 99,4 & & 12.590 & 68,8 & & 4.737 & 25,9 & & \\
\hline Total & 18.312 & 100,0 & & 18.312 & 100,0 & & 18.312 & 100,0 & & \\
\hline
\end{tabular}

Fonte: Autor, a partir do survey Pesquisa Brasileira de Mídia 2014 (BRASIL, 2013).

Para integrar o ICI, as informaçôes sobre uso em cada uma das três posiçôes serão transformadas em variáveis dicotômicas com pesos proporcionais à posição que ele apresenta o uso da internet. Se o respondente diz usar a internet em primeiro lugar, ele receberá código 3. Todos os demais terão código zero. Se diz usar a internet em segundo lugar, receberá código 2. Todos os demais, código zero. Se diz usar a internet em terceiro lugar, código 1 . Todos os demais, código zero. Com isso teremos uma escala de 3 a 1 para diferenciar a importância da internet para os 6.845 respondentes que disseram usar a internet em uma das três posiçóes relatadas na pesquisa. Os demais 11.467 respondentes que não citaram internet em nenhuma das três posiçôes receberão código zero, ou seja, não terão peso na composição do ICI. Logo, a amplitude total será de três a zero.

A segunda questão diz respeito a qual meio de comunicação o respondente mais usa para se informar. Aqui, são duas posiçôes: em primeiro lugar e em segundo lugar. A Tabela 2 a seguir sumariza as informaçóes para essas perguntas. Novamente, em primeiro lugar aparece a TV, com $78,4 \%$ das respostas válidas, seguida da internet, com 12,9\%. Na segunda opção de principal meio de informação o Rádio aparece como principal resposta, com 40,7\%, seguido da internet, com 27,3\%, e depois da TV, com 21\%. Todos os demais meios apresentam percentuais muito 
baixos. Quando somamos todas as respostas válidas para as duas posiçóes temos que 99,4\% dos respondentes diz se informar pela TV em primeiro ou segundo lugar. Em seguida vem o rádio como meio de informação para $47 \%$ dos entrevistados. $\mathrm{Na}$ terceira posição fica a internet, com $40,2 \%$ de respostas.

As duas variáveis analisadas até aqui apresentam comportamentos muito semelhantes, pois os percentuais de respostas para uso e busca de informaçáo seguem os mesmos padrôes. Em primeiro lugar TV, seguida de rádio e internet. E nos dois casos a internet aparece em maior proporção na segunda ou terceira opção entre os meios apresentados aos respondentes. Adicionalmente, os veículos impressos, jornal e revista, aparecem sempre como os menos citados, tanto em termos de uso quanto de fonte de informação.

Tabela 2 - Respostas às questôes: "Em que meio de comunicação o(a) senhor(a) se informa mais sobre o que acontece no Brasil?" por ordem de classificação

\begin{tabular}{l|r|r|r|r|r|r|r}
\hline \multirow{2}{*}{ Meios de Comunicaçáo } & \multicolumn{3}{|c|}{$1^{\circ}$ Lugar } & \multicolumn{3}{c|}{ 20 Lugar $^{\text {Total }}$} \\
\cline { 2 - 8 } & $\mathrm{N}$ & \% & \%vál. & $\mathrm{N}$ & \% & \%vál. & $\begin{array}{c}\text { Soma } \\
\text { \%vál. }\end{array}$ \\
\hline TV & 14.260 & 77,9 & 78,4 & 2.078 & 11,3 & 21,0 & 99,4 \\
\hline Rádio & 1.144 & 6,2 & 6,3 & 4.021 & 22,0 & 40,7 & 47,0 \\
\hline Jornal impresso & 349 & 1,9 & 1,9 & 910 & 5,0 & 9,2 & 11,1 \\
\hline Revista impressa & 69 & 0,4 & 0,4 & 175 & 1,0 & 1,8 & 2,2 \\
\hline Internet & 2.355 & 12,9 & 12,9 & 2.694 & 14,7 & 27,3 & 40,2 \\
\hline Panfletos & 1 & 0,0 & 0,0 & 0 & 0,0 & 0,0 & 0,0 \\
\hline Conversa com amigos/parentes & 13 & 0,1 & 0,1 & 0 & 0,0 & 0,0 & 0,1 \\
\hline Outros/não se aplica & 121 & 0,7 & & 8.434 & 46,1 & & \\
\hline Total Válido & 18.191 & 99,3 & & 8.878 & 53,9 & & \\
\hline Total & 18.312 & 100,0 & & 18.312 & 100,0 & & \\
\hline
\end{tabular}

Fonte: Autor, a partir do survey Pesquisa Brasileira de Mídia 2014 (BRASIL, 2013).

Aqui, para compor o ICI, o procedimento será o mesmo que relatado anteriormente, com transformaçóes de valores. As respostas são transformadas em binárias. Quem respondeu que internet está em primeiro lugar como fonte de informaçáo receberá código 2 e os demais, código zero. Quem respondeu que a internet está em segundo lugar como fonte de informação receberá código 1 e os demais, código zero. Assim, reunindo as duas informaçôes teremos uma escala que vai de 2 a zero, sendo que no código 2 a internet é a principal fonte de informaçáo, no código 1 ela é a segunda fonte de informação e no código zero ela não é citada como fonte de informação. Isso significa que das 18.312 entrevistas, apenas 5.049 serão 
consideradas válidas para esse item do índice, as que responderam internet como primeira ou segunda opção.

O terceiro item do índice é obtido a partir das respostas às perguntas de quantas horas por dia, em média, o entrevistado navega na internet entre segundafeira e sexta-feira e aos finais de semana. Aqui estamos utilizando apenas as respostas em horas cheias. Como se trata de uma variável quantitativa de razão, a Tabela 3 a seguir sumariza as principais estatísticas de cada uma delas, além de indicar as médias das duas variáveis isoladas. As duas variáveis originais são de segunda-feira a sextafeira e aos finais de semana. Percebe-se que em média o brasileiro que navega na internet passa 3,62 horas por dia durante a semana e 3,7 horas por dia aos finais de semana. A mediana é a mesma para os dois casos, de 3 horas por dia, o que significa que metade dos usuários passa até três horas em qualquer dia da semana. $\mathrm{O}$ desvio padrão é alto nos dois casos, pois há valores extremos com pessoas indicando navegar até $23 \mathrm{~h}$ por dia.

Uma informação importante está na comparação dos casos válidos para as duas variáveis originais. Entre os que dizem acessar a internet durante a semana temos 7,9 mil, contra 6,1 mil entre os que dizem acessar internet aos finais de semana. A diferença indica que no Brasil ainda existe um contingente razoável, impossível de ser precisado aqui, de pessoas que só acessam a internet do trabalho, durante os dias de semana e que, portanto, provavelmente não contam com o serviço de provedor doméstico de internet. Dos que disseram acessar internet pelo menos uma hora por dia durante entre segunda-feira e sexta-feira, 203 responderam que não navegavam durante os finais de semana. E dos que indicaram navegar pelo menos uma hora por dia aos finais de semana, 113 responderam navegar menos uma hora por dia entre segunda-feira e sexta-feira. A média das informaçóes das duas variáveis originais resultará no item que será usado na composição ICI, pois o que nos interessa é o tempo de uso geral da internet e não em períodos específicos. A variável "tempo médio" na Tabela 3 foi construída a partir das duas anteriores. Náo se trata de uma média aritmética simples, como é possível perceber de imediato no número de respondentes $(\mathrm{N})$. Há 8.063 respondentes considerados para o "tempo médio" porque como indicado anteriormente alguns respondentes navegam apenas durante a semana e outros exclusivamente nos finais de semana. Para calcular o "tempo médio", foram considerados todos que indicaram pelo menos uma hora de navegação em um dos períodos de tempo. 
Tabela 3 - Tempo médio de uso da internet

\begin{tabular}{l|r|r|r}
\hline \multicolumn{1}{c|}{ Estatísticas } & De 2a-feira a 6a-feira & Finais de semana & \multicolumn{1}{c}{ Tempo Médio } \\
\hline Média & 3,62 horas/dia & 3,70 horas/dia & 3,47 horas/dia \\
\hline Mediana & 3,00 horas/dia & 3,00 horas/dia & 2,50 horas/dia \\
\hline Desvio Padrão & 3,68 horas/dia & 3,47 horas/dia & 3,35 horas/dia \\
\hline $\mathrm{N}$ & 7.938 & 6.133 & 8.063 \\
\hline
\end{tabular}

Fonte: Autor, a partir do survey Pesquisa Brasileira de Mídia 2014 (BRASIL, 2013).

O resultado é que, em média, o brasileiro navega 3,47 horas/dia, com mediana de 2,5 horas/dia9 . Significa que ao reunirmos informaçôes sobre os que navegam apenas durante a semana, apenas aos finais de semana e nos dois períodos há uma queda no tempo de navegação. Essa diferença no tempo de navegação não seria percebida caso se considerasse apenas um dos períodos isoladamente.

Para integrar o índice, a variável tempo será categorizada pela fórmula de Sturges $^{10}$, onde os intervalos entre categorias são os mesmos e a variação se dá no número de casos dentro de cada categoria. A partir do uso da fórmula de Sturges, tem-se a indicação da divisão do tempo médio de navegação em 14 categorias. Como o número de categoria é muito alto e dificulta a interpretação dos resultados, decidimos reduzir à metade, chegando a sete categorias, representadas da seguinte forma em número de horas de navegação: i) muito baixa, ii) baixa, iii) média baixa, iv) média, v) média alta, vi) alta e vii) muito alta. A distribuição dos casos em cada uma das categorias é representada na Tabela 4 a seguir.

Antes de distribuir os casos nas categorias pela fórmula de Sturges foi identificado que acima de 10 horas estão apenas casos extremos. Por isso, o intervalo considerado para as categorias foi entre menos de uma hora e até 10 horas. Os casos extremos foram inseridos na categoria "muito alta".

\footnotetext{
${ }^{9} \mathrm{Na}$ pesquisa 2015 da PBM há um ajuste da pergunta, descrevendo o uso hora a hora em todos os meios. Isso torna as respostas mais precisas.

${ }^{10}$ A fórmula foi proposta por Herbert Sturges em 1926 como uma regra a se considerar sobre o número de classes a partir da distribuição de um histograma. A fórmula é $\mathrm{k}=1+3,332 \times \log \mathrm{N}$. (BUNCHAFT e KELLNER, 1999).
} 
Tabela 4 - Categorização da média de horas navegação

\begin{tabular}{l|c|r|r|r}
\hline \multicolumn{1}{c|}{ Categoria } & Intervalo horas & \multicolumn{1}{c|}{$\mathrm{N}$} & \multicolumn{1}{c}{ \%val. } \\
\hline Muito baixa & 0,00 a 1,43 & 2.098 & 11,5 & 26,0 \\
\hline Baixa & 1,44 a 2,87 & 2.117 & 11,6 & 26,3 \\
\hline Média baixa & 2,88 a 4,31 & 1.693 & 9,2 & 21,0 \\
\hline Média & 4,32 a 5,75 & 779 & 4,3 & 9,7 \\
\hline Média alta & 5,76 a 7,19 & 521 & 2,8 & 6,5 \\
\hline Alta & 7,20 a 8,63 & 310 & 1,7 & 3,8 \\
\hline Muita alta & 8,64 a 10,0 & 545 & 3,0 & 6,8 \\
\hline Total Válido & & 8.063 & 44,0 & 100,0 \\
\hline Náo Válido & & 10.249 & 56,0 & \\
\hline Total Geral & & 18.312 & 100,0 & \\
\hline
\end{tabular}

Fonte: Autor, a partir do survey Pesquisa Brasileira de Mídia 2014 (BRASIL, 2013).

Como se pode perceber na Tabela acima, 52,3\% dos que dizem navegar na internet apresentam uma média de até 2,87 horas por dia, ficando próximo da mediana de 2,5 horas para a variável contínua (ver Tabela 3). As sete categorias da variável de tempo de navegação serão inseridas no índice aditivo.

A quarta e última variável do ICI não pertence à dimensão quantitativa, mas sim à qualitativa da avaliação. Ela diz respeito à confiança que o respondente da pesquisa tem nos conteúdos que recebe da internet. Foram realizadas três perguntas, uma para cada tipo de fonte de informação na internet: sites, blogs e redes sociais. As alternativas para respostas válidas eram: "confia sempre", "confia muitas vezes", "confia poucas vezes" e "nunca confia". A Tabela 5 a seguir mostra que os níveis de confiança em sites, blogs e redes sociais são muito parecidos. As duas categorias centrais (confia muitas e confia poucas vezes) juntas reúnem quase $75 \%$ do total. As médias dos percentuais válidos mostram que apenas $6,1 \%$ dos usuários dizem confiar sempre nos conteúdos da internet. A maior confiança é em sites, com 6,9\% e a menor em blogs, com 5,2\%. Essa tendência se repetirá em todas as demais categorias, com os sites reunindo os maiores percentuais de confiança e os blogs ficando abaixo nos níveis de confiança. De maneira geral, as redes sociais inspiram mais confiança que os blogs e menos que os sites. Na média, além dos 6,1\% que dizem confiar sempre nos conteúdos da internet, $19,4 \%$ diz confiar muitas vezes; 55,7\% dizem confiar poucas vezes e $18,9 \%$ diz nunca confiar nesses conteúdos. 
Tabela 5 - Respostas às perguntas: "Gostaria de saber quanto o(a) senhor(a) confia em notícias que circulam nos diferentes meios de comunicação"

\begin{tabular}{|c|c|c|c|c|c|c|c|c|c|c|}
\hline \multirow[t]{2}{*}{ Categorias } & \multicolumn{3}{|c|}{ Sites } & \multicolumn{3}{|c|}{ Blogs } & \multicolumn{3}{|c|}{ Redes Sociais } & \multirow{2}{*}{$\begin{array}{l}\text { Média } \\
\text { \%vál. }\end{array}$} \\
\hline & $\mathrm{N}$ & $\%$ & \%val. & $\mathrm{N}$ & $\%$ & \%val. & $\mathrm{N}$ & $\%$ & \%val. & \\
\hline $\begin{array}{l}\text { Confia } \\
\text { Sempre }\end{array}$ & 563 & 3,1 & 6,9 & 411 & 2,2 & 5,2 & 500 & 2,7 & 6,2 & 6,1 \\
\hline $\begin{array}{l}\text { Confia } \\
\text { muitas } \\
\text { vezes }\end{array}$ & 1.742 & 9,5 & 21,4 & 1.442 & 7,9 & 18,1 & 1.508 & 8,2 & 18,6 & 19,4 \\
\hline $\begin{array}{l}\text { Confia } \\
\text { poucas } \\
\text { vezes }\end{array}$ & 4.499 & 24,6 & 55,4 & 4.469 & 24,4 & 56,0 & 4.503 & 24,6 & 55,6 & 55,7 \\
\hline $\begin{array}{l}\text { Nunca } \\
\text { Confia }\end{array}$ & 1.318 & 7,2 & 16,2 & 1.655 & 9,0 & 20,7 & 1.592 & 8,7 & 19,6 & 18,9 \\
\hline $\begin{array}{l}\text { Total } \\
\text { Válido }\end{array}$ & 8.122 & 44,4 & 100,0 & 7.977 & 43,6 & 100,0 & 8.103 & 44,2 & 100,0 & \\
\hline $\begin{array}{l}\text { Náo se } \\
\text { aplica }\end{array}$ & 10.190 & 55,6 & & 10.335 & 56,4 & & 10.209 & 55,8 & & \\
\hline Total & 18.312 & 100,0 & & 18.312 & 100,0 & & 18.312 & 100,0 & & \\
\hline
\end{tabular}

Fonte: Autor, a partir do survey Pesquisa Brasileira de Mídia 2014 (BRASIL, 2013).

Para inserir a variável "confiança" no índice os códigos foram somados, criando uma nova dimensão, que está dividida em três pontos: (i) confiança baixa; (ii) confiança média e (iii) confiança alta nos conteúdos que recebe da internet. Para isso, foi considerado o número de casos que apresentou pelo menos uma resposta válida entre as três variáveis, que é 8.172 respostas. Uma vez agrupadas as respostas, os grupos de níveis de confiança ficaram da seguinte forma: Categoria 1 - Confiança baixa, 1.932 respondentes (23,6\%); Categoria 2 - Confiança média, 4.764 respondentes (58,3\%); e Categoria 3 - Confiança alta, 1.472 respondentes $(18,1 \%)$.

Até aqui foram descritas as variáveis que compóem o índice. O próximo passo é fazer a soma dos códigos das categorias. Os índices aditivos são o resultado da soma de códigos de diferentes variáveis que indicam mudanças na mesma direção. No caso, quanto maior o valor do código, mais intenso é o uso ou maior a confiança que o entrevistado indica ter em conteúdos que recebe da internet. Considerando as variáveis e as categorias utilizadas aqui, o menor valor do índice terá código dois e indicará o entrevistado que não colocou internet entre as três opções de uso de meios de comunicação e entre as duas fontes principais de notícias, mas indicou um tempo de uso muito baixo por dia e apresentou baixa confiança nos conteúdos transmitidos pela internet. Na outra extremidade do índice está o código 15, que indica o 
respondente que citou internet em primeiro lugar como veículo de comunicação, em primeiro lugar como fonte de informação, que se encontra na categoria "muita alta" de tempo de navegaçáo diária e confia muito nos conteúdos transmitidos pela internet. Isso significa que o índice tem uma amplitude de 13 pontos, variando de no mínimo dois ao máximo de 15 pontos. Para resumir as etapas de construçáo, o Quadro 2 a seguir mostra todas as variáveis que compóem o índice.

Quadro 2 - Sumário da composição inicial do Índice de Centralidade da Internet

\begin{tabular}{|c|c|c|}
\hline Variável & Categorias & Posiçáo no ICI \\
\hline Uso de Internet & $\begin{array}{l}0 \text { - não usa } \\
1 \text { - usa em } 3^{\circ} \text { lugar } \\
2 \text { - usa em } 2^{\circ} \text { lugar } \\
3 \text { - usa em } 1^{\circ} \text { lugar }\end{array}$ & \multirow{4}{*}{$\begin{array}{l}\text { 2- Centralidade mais baixa (diz não usar e não } \\
\text { buscar informaçóes na internet; tem tempo de } \\
\text { navegação muito baixo e confiança baixa); } \\
\text {... } \\
8 \text { - Centralidade média (indica algum uso de } \\
\text { internet e a busca de informaçóes no meio; tem } \\
\text { tempo de navegação e alguma confiança); } \\
\text {... } \\
15 \text { - Centralidade mais alta (usa e busca } \\
\text { informaçóes principalmente na internet; tem } \\
\text { tempo de navegação muito alto e alta confiança } \\
\text { nos conteúdos). }\end{array}$} \\
\hline $\begin{array}{l}\text { Informação na } \\
\text { internet }\end{array}$ & $\begin{array}{l}0 \text { - náo busca } \\
1 \text { - busca em } 2^{\circ} \text { lugar } \\
2 \text { - busca em } 1^{\circ} \text { lugar }\end{array}$ & \\
\hline Tempo de navegação & $\begin{array}{l}1 \text { - muito baixa } \\
2 \text { - baixa } \\
3 \text {-média baixa } \\
4 \text { - média } \\
5 \text { - média alta } \\
6 \text { - alta } \\
7 \text { - muito alta }\end{array}$ & \\
\hline Confiança na internet & $\begin{array}{l}1 \text { - baixa } \\
2 \text { - média } \\
3 \text { - alta }\end{array}$ & \\
\hline
\end{tabular}

Fonte: Autor, a partir da Pesquisa Brasileira de Mídia 2014 (BRASIL, 2013).

Com a composição descrita no Quadro acima, o ICI teria uma variação de 13 pontos originalmente, que se reunidos a cada par, com trios no segundo e quarto postos, resultaria em uma escala de cinco pontos, também conhecida como Escala de Likert, que nesse caso variaria de: i) centralidade muito baixa (posiçóes 2, 3 e 4); ii) centralidade baixa (posiçóes 5, 6 e 7); iii) centralidade média (posiçóes 8 e 9); iv) centralidade alta (posiçôes 10, 11 e 12) e v) centralidade muito alta (posiçóes 13, 14 e $15)$.

Ainda que do ponto de vista conceitual, a escala aditiva proposta até aqui seja consistente, isso não é suficiente para garantir a validade do índice. É preciso testar os itens e as relaçóes entre as variaçóes deles antes de concluir a construção do mesmo. $\mathrm{O}$ teste mais popular de confiabilidade de um índice foi proposta por Lee J. Cronbach em 1951 e produz um coeficiente que indica quanto da variação dos itens é explicada 
pelo índice proposto. Esse coeficiente é chamado de " $\alpha$ de Cronbrach" (BUNCHAFT e KELLNER, 1999). O objetivo do próximo tópico é descrever os princípios teóricos da confiabilidade para índices e testar as variaçôes dos quatro itens inseridos no ICI.

\section{Teste de confiabilidade para ICI}

$\mathrm{O} \alpha$ de Cronbach é um teste utilizado para validar uma proposta teórica de índice a partir da reuniáo de diferentes variáveis. Ainda que os componentes pretendidos para o índice tenham validade teórica, sem a validação não há nenhuma garantia de que as variaçôes totais das características apresentem alguma consistência empírica. De acordo com Cronbach (1971), o teste de validação verifica se um instrumento de medida é válido para testar um tipo específico de fenômeno assim como poderia testar outro fenômeno. A validação não identifica as relaçóes do instrumento de medida com outras variáveis, mas sim os instrumentos em relação a si mesmo. No caso, o instrumento é o ICI.

Para identificar a força de um instrumento em relação a si mesmo, parte-se do princípio que as variaçóes internas devam ser consistentes, ou seja, indicarem variaçôes na mesma direção (CARMINE e ZELLER, 1979). O teste $\alpha$ de Cronbach é calculado a partir das variaçóes individuais e totais de todos os itens de um índice. $\mathrm{O}$ objetivo da validaçáo que interessa a este trabalho é obtido a partir do teste de Construct-validity para identificar o tipo de relação existente entre conceitos e teorias com suas representaçóes empíricas, indicando quanto um conceito teórico é válido em determinado contexto. No caso, quanto às diferentes formas de uso da internet são capazes de representar o conceito de "centralidade". Esse tipo de validaçáo parte da relação entre os conceitos para ser aplicado em uma evidência específica. É usado para verificar se uma medida empírica é válida em determinado contexto, explicando o desempenho de determinada medida empírica, em função das expectativas teóricas. Caso sejam identificadas inconsistências entre as expectativas teóricas e as medidas empíricas, isso significa que as medidas não representam da forma esperada o conceito teórico. Em outras palavras, a medida empírica apresenta falhas de construçáo para um conceito particular (CARMINE e ZELLER, 1979).

A lógica de um teste de validação sustenta-se na medida de confiabilidade daquilo que é representado pelos resultados obtidos. Quanto menor a variação não explicada, mais confiável será a medida e, portanto, maior a validade para representar determinado conceito. A equação abaixo representa essa relação:

$$
\mathrm{x}=\mathrm{t}+\mathrm{e}
$$


Onde " $x$ " é a medida empírica a ser estudada, que é composta por dois elementos: " $t$ " que é a parte explicada da variação e " $e$ " que é o erro randômico, ou seja, a parte não explicada e que não apresenta nenhuma tendência. Em toda medida validada os valores esperados são hipotéticos e não podem ser medidos diretamente. $\mathrm{Na}$ possibilidade de medir diretamente a relaçáo entre um conceito teórico e uma variável empírica, o teste de validação perde o sentido de existir. Os valores apresentados em um teste como esse sáo aqueles obtidos em um conjunto de mediçôes realizadas em determinado período de tempo e como nenhuma medida individual pode ser representativa do valor real, usa-se a estimaçáo de confiabilidade para indicar quanto podem ser confiáveis os resultados obtidos em determinado conjunto de observaçóes. $\mathrm{O}$ erro randômico representa um conjunto de distúrbios ou variaçôes não explicadas no momento em que a medida é tomada ${ }^{11}$. Existem erros positivos e negativos e, se forem randômicos, terão a mesma magnitude, ou seja, ao final eles se anularão. Se isso não acontecer, os erros não serão randômicos e passarão a ser tendenciosos. Assim, a primeira hipótese de um teste de validação é que a soma dos erros equivale a zero, a média dos erros deve ser zero e a correlaçáo entre os erros de uma variável e os erros de outra também deve ser zero. Sendo assim, um teste de confiabilidade parte da razão de variâncias. Quanto maior a variância real, menor o erro randômico e maior a confiabilidade da medida. Em outras palavras, uma medida de confiabilidade é a correlação entre medidas paralelas de variâncias (CARMINE e ZELLER, 1979). O $\alpha$ de Cronbach é uma das medidas de confiabilidade mais conhecidas e pode ser expressa de duas formas ${ }^{12}$.

Aplicando o teste às quatro variáveis que compóem inicialmente o ICI encontramos um coeficiente $\alpha$ de Cronbach de 0,443, portanto, muito baixo. Para ser um índice que represente empiricamente os conceitos teóricos espera-se a obtenção de um coeficiente de pelo menos 0,700. A Tabela 6.1 abaixo apresenta os primeiros indícios para a inconsistência do índice. A matriz de correlação mostra que as maiores correlaçôes entre as variáveis se dão entre "uso da internet" e "busca por informaçóes"

\footnotetext{
${ }^{11}$ Não se deve confundir consistência interna com homogeneidade (CORTINA, 1993).

${ }^{12}$ Quando as variâncias são conhecidas a fórmula é:

$\boldsymbol{*}=\frac{N}{\omega-1\rangle\left[\frac{\left.1-5 \sigma^{2} \hat{\beta}^{2}\right)}{\sigma_{x}^{2}}\right]}$
}

Onde: $\mathrm{N}=$ número de itens; $\Sigma \sigma^{2}\left(\varphi_{0}\right)$ soma da variância dos itens; $\sigma_{x}^{2}=$ variância total. Quando se conhece a matriz de correlação entre as variáveis a expressão pode ser simplificada a:

$\approx=\frac{N_{\varphi}}{[1-\rho(N-1)]}$

Onde: $\mathrm{N}=$ número de itens; $\rho=$ média da correlação entre itens. 
(0,472). A variável "tempo de navegação" apresenta coeficientes de correlação pouco acima de 0,200 para as duas variáveis anteriores. Porém, As correlaçóes mais baixas estão na variável "confia nos conteúdos", todas abaixo de 0,050 . Isso indica que a causa dos distúrbios não explicados no índice deva ser a presença da variável "confia nos conteúdos".

Tabela 6 - Correlaçấo entre itens e efeito da exclusão por item

\begin{tabular}{|c|c|c|c|c|c|}
\hline \multicolumn{5}{|c|}{ Matriz de correlaçáo entre itens } & \multirow{2}{*}{$\begin{array}{c}\alpha \text { de Cronbach } \\
\text { se o item } \\
\text { for excluído }\end{array}$} \\
\hline & $\begin{array}{c}\text { Uso } \\
\text { Internet }\end{array}$ & $\begin{array}{c}\text { Busca } \\
\text { Informaçōes }\end{array}$ & $\begin{array}{c}\text { Horas } \\
\text { navegaçáo }\end{array}$ & $\begin{array}{c}\text { Confia } \\
\text { conteúdos }\end{array}$ & \\
\hline Uso Internet & & 0,472 & 0,249 & 0,019 & 0,259 \\
\hline Busca Informaçóes & 0,472 & & 0,256 & 0,053 & 0,272 \\
\hline Horas Navegaçáo & 0,249 & 0,256 & & 0,034 & 0,435 \\
\hline Confia conteúdos & 0,019 & 0,053 & 0,034 & & 0,506 \\
\hline
\end{tabular}

Coeficiente $\alpha$ de Cronbach $=0,443$ (4 itens)

Fonte: Autor, a partir da Pesquisa Brasileira de Mídia 2014 (BRASIL, 2013).

A última coluna da Tabela acima indica qual seria o coeficiente $\alpha$ de Cronbach caso o item fosse excluído do índice. Percebe-se que a exclusão das duas primeiras variáveis reduziria bastante o coeficiente, fazendo-o cair para cerca de 0,200 . Porém, a exclusão da variável "confia nos conteúdos" elevaria o coeficiente para 0,506. Embora ainda não seja aceitável, o coeficiente melhoraria sem a quarta variável. Para concluir a análise da proposta inicial de composição do índice, o Gráfico 2 mostra a proporçáo de "carregamento" de cada variável na composição bidimensional do índice. Percebese claramente que a variável "confiança nos conteúdos" encontra-se em uma dimensão que não é a mesma das outras três variáveis. Assim, a técnica de validação de índice a partir do coeficiente $\alpha$ de Cronbach nos mostra que a inclusão dessa variável no índice aumenta a proporção de variaçáo não explicada nos casos e, portanto, deve ser excluída. 
Gráfico 2 - Carregamento dos itens por dimensão

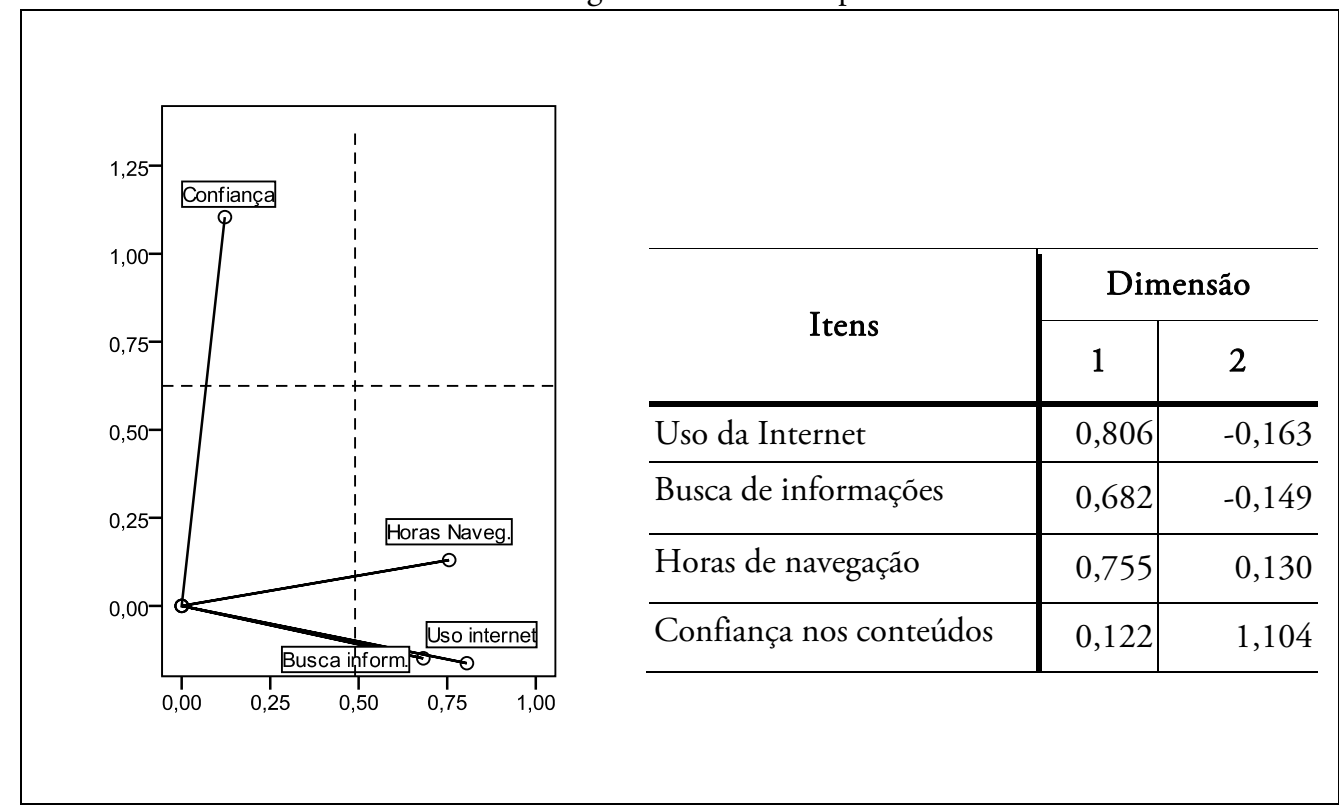

Fonte: Autor, a partir da Pesquisa Brasileira de Mídia 2014 (BRASIL, 2013).

Uma análise mais detida do Gráfico acima indica que o distanciamento da "confiança nos conteúdos" em relação às outras três variáveis pode estar encobrindo outro conjunto de variaçóes náo explicadas. Trata-se do efeito da variável "horas de navegação" no índice. Embora ela esteja próxima das outras duas, quando considerados os quatro itens, no momento em que se excluir a "confiança nos conteúdos" é possível que "horas de navegação" passe a causar os distúrbios não explicados nas variaçôes do índice. Por isso, testaremos o índice com as três variáveis e com apenas as duas primeiras para conhecer os resultados comparativos de confiabilidade. Os coeficientes obtidos estão resumidos no Quadro a seguir:

Quadro 3 - Resultados dos testes de $\alpha$ de Cronbach para três modelos de índice

\begin{tabular}{|l|l|r|}
\hline $\mathrm{N}$ itens & Variáveis & $\boldsymbol{\alpha}$ \\
\hline 4 & $\begin{array}{l}\text { Uso Internet+Busca Informaçóes+Horas Navegação+Confiança nos } \\
\text { conteúdos }\end{array}$ & 0,443 \\
\hline 3 & Uso Internet + Busca Informaçóes + Horas Navegação & 0,506 \\
\hline 2 & Uso Internet + Busca Informaçóes & 0,788 \\
\hline
\end{tabular}

Fonte: Autor, a partir da Pesquisa Brasileira de Mídia 2014 (BRASIL, 2013).

O Quadro 3 evidencia que ao contrário do que relata a literatura, neste caso o maior número de variáveis reduziu a capacidade explicativa do ICI. O único 
coeficiente aceitável (acima de 0,700) obtido a partir das variáveis disponíveis na Pesquisa Brasileira do Uso de Mídia é o que reúne apenas as respostas ao "uso da internet" e à "busca por informaçôes" na internet. Dado esse resultado, excluiremos as duas variáveis que não contribuem com as explicaçôes e montaremos o ICI apenas com uso e busca de informaçóes. Dessa forma, o índice de Centralidade da Internet passa a ter a seguinte composição:

Quadro 4 - Sumário da composição final do Índice de Centralidade da Internet

\begin{tabular}{|c|c|c|}
\hline Variável & Categorias & Posiçáo no ICI \\
\hline Uso de Internet & $\begin{array}{l}0 \text { - não usa } \\
1 \text { - usa em } 3^{\circ} \text { lugar } \\
2 \text { - usa em } 2^{\circ} \text { lugar } \\
3 \text { - usa em } 1^{\circ} \text { lugar }\end{array}$ & $\begin{array}{l}0 \text { - Nenhuma centralidade } \\
1 \text { - Centralidade muito baixa } \\
2 \text { - Centralidade baixa }\end{array}$ \\
\hline $\begin{array}{l}\text { Informação na } \\
\text { internet }\end{array}$ & $\begin{array}{l}0 \text { - não busca } \\
1 \text { - busca em } 2^{\circ} \text { lugar } \\
2 \text { - busca em } 1^{\circ} \text { lugar }\end{array}$ & $\begin{array}{l}3 \text { - Centralidade média } \\
4 \text { - Centralidade alta } \\
5 \text { - Centralidade muito alta }\end{array}$ \\
\hline
\end{tabular}

Fonte: Autor, a partir da Pesquisa Brasileira de Mídia 2014 (BRASIL, 2013).

Com isso, se considerarmos que o valor zero é a ausência de indicadores para uso de internet, as outras cinco categorias formam uma escala de Likert, o que nos permitirá identificar mudanças proporcionais entre centralidade alta e centralidade baixa, assim como medir o peso da posição média no ICI. A distribuição das frequências de casos em cada uma das categorias do Índice de Centralidade é apresentada na Tabela 7 . De acordo com a pesquisa, temos 39,1\% de brasileiros usando a internet e citando-a como fonte de informação. No entanto, 60,9\% dos respondentes não apresentam nenhum ponto no ICI. Dos que citam internet a distribuição é equilibrada entre os que apresentam baixa centralidade, média centralidade e alta centralidade, com distribuiçóes de praticamente $1 / 3$ de casos para cada um dos grupos. A diferença é que no grupo de baixa centralidade, a categoria "baixa" representa a maior parte (20,5\%), enquanto que no grupo de alta centralidade, a categoria "muito alta" é a que representa a maior parte $(19,8 \%)$. 
Tabela 7 - Frequências das Categorias no Índice de Centralidade da Internet

\begin{tabular}{l|r|r|r}
\hline Categoria & $\mathrm{N}$ & \% & \%val. \\
\hline Muito baixa & 1.006 & 5,5 & 14,1 \\
\hline Baixa & 1.470 & 8,0 & 20,5 \\
\hline Média & 2.351 & 12,8 & 32,8 \\
\hline Alta & 916 & 5,0 & 12,8 \\
\hline Muito alta & 1.417 & 7,7 & 19,8 \\
\hline Total válido & 7.160 & 39,1 & 100,0 \\
\hline Nenhuma & 11.152 & 60,9 & \\
\hline Total Geral & 18.312 & 100,0 & \\
\hline Fon & & &
\end{tabular}

Fonte: Autor.

Concluída a construção do ICI, no próximo tópico será feito o cruzamento do índice com variáveis socioeconômicas e geoGráficas para identificar possíveis padróes de centralidade de internet por sexo, idade, escolaridade, renda, porte do município e região geoGráfica de moradia. Para isso, os testes terão duas etapas: (i) teste entre nenhuma centralidade e alguma centralidade, com o objetivo de identificar que variáveis socioeconômicas e geoGráficas concentram maiores proporçôes dos $60,9 \%$ de respondentes sem nenhuma centralidade ou 39,1\% dos que apresentam alguma centralidade; e (ii) testar apenas os casos com alguma centralidade para verificar que características são mais comuns entre os usuários com alta, média e baixa centralidade.

\section{Quem é o usuário de alta centralidade de internet}

A caracterização socioeconômica e geoGráfica do usuário de internet no Brasil é composta por oito variáveis, sendo cinco delas de caráter individual e outras três que reúnem dados agregados. O primeiro grupo é composto por: (i) sexo (código 1=homem, 2=mulher); (ii) idade do entrevistado, a partir de 16 anos; (iii) escolaridade em categorias (de $1=$ analfabeto ... até $10=$ curso superior completo); (iv) Renda pessoal e (v) Renda familiar, ambas categorizadas e com os mesmos intervalos ( $1=$ até $\mathrm{R} \$ 678,00,2=$ de 678,00 a $1.356,00 \ldots$ até $6=$ mais de $\mathrm{R} \$ 13.560,01)$. As três variáveis agregadas inseridas no modelo são: (i) Condição do município de moradia do entrevistado ( 1 =capital, 2 =periferia, 3 =interior); (ii) porte do município ( $1=$ até 20 mil habitantes... até $7=$ mais de $500 \mathrm{mil}$ ) e (iii) regiáo (1=norte, $2=$ nordeste, $3=$ sudeste, $4=$ sul e $5=$ centro-sul).

Para testar a importância de cada característica socioeconômica e geoGráfica na centralidade da internet para o brasileiro começaremos com uma regressáo binária entre as oito variáveis explicativas apresentadas acima e o fato de a internet ser ou não 
ser citada pelo respondente à pesquisa nacional. Os códigos são $0=$ não ter centralidade e $1=$ ter alguma centralidade. A função de uma regressão logística é indicar uma probabilidade de ocorrência de determinado fenômeno, no caso indicar ou não centralidade da internet, dada a mudança na variável independente.

Antes de analisar os resultados de uma regressão logística com mais de uma variável explicativa é preciso verificar a existência de colinearidade entre as variáveis do modelo. Se houver colinearidade entre as variáveis torna-se impossível a leitura dos coeficientes do modelo proposto inicialmente, sendo necessária a exclusão das características que geram colinearidade ${ }^{13}$. As principais estatísticas do modelo e as estatísticas individuais são apresentadas na Tabela 8 a seguir. As três principais estatísticas do modelo são o qui-quadrado $\left(\chi^{2}\right)$, o coeficiente -2loglikelihood e o $\mathrm{r}^{2}$ de Cox \& Snell. As duas primeiras mostram quanto o modelo como um todo explica a mudança entre não ter valor válido no ICI e apresentar alguma centralidade. Como os valores são altos, $\operatorname{com} \chi^{2}=6.608,59$ e sig $(0,000)$, indicando que pelo menos uma ou algumas variáveis explicativas são estatisticamente significativas. $\mathrm{O} \mathrm{r}^{2}$ de $\operatorname{Cox} \&$ Snell mostra quanto que esse conjunto de características pode explicar mudanças. Esse indicador é mais importante quando se pretende usar o teste para fazer prediçáo, ou seja, identificar possíveis comportamentos no futuro. $\mathrm{O}$ coeficiente de 0,386 indica que a capacidade preditiva do modelo é de $38,6 \%$ apenas, ou seja, outros $61,4 \%$ das variaçôes não são explicados pelas variáveis inseridas no modelo.

${ }^{13}$ Existem dois testes de colinearidade para as regressôes. O coeficiente de tolerância, que deve estar acima de 0,010 para que a variável não seja linear. De forma complementar, o coeficiente VIF indica colinearidade quando os valores ficam acima de 10,0. O Quadro abaixo mostra os coeficientes de Tolerância e FIF para as oito variáveis do modelo. Como podemos perceber, todas as variáveis do modelo passaram pelos dois testes de colinearidade e podem ser inseridas na regressão logística para medir que características explicam a centralidade da internet para o brasileiro.

\begin{tabular}{|l|l|l|}
\hline Variável & Tolerância & VIF \\
\hline Sexo & 0,936 & 1,068 \\
\hline Idade & 0,720 & 1,390 \\
\hline Escolaridade & 0,553 & 1,807 \\
\hline Renda pessoal em salários mínimos & 0,416 & 2,405 \\
\hline Renda familiar em salários mínimos & 0,417 & 2,400 \\
\hline Condição do município & 0,490 & 2,039 \\
\hline Porte do município & 0,495 & 2,021 \\
\hline Região & 0,939 & 1,065 \\
\hline
\end{tabular}


O principal interesse aqui é o efeito individual das variáveis explicativas sobre o fato de a internet ter ou não centralidade para o entrevistado. $\mathrm{O}$ coeficiente ROA indica quanto cada variável contribui individualmente para a presença ou não do ICI. Nota-se que todas as variáveis apresentam significância abaixo do limite crítico, ou seja, são todas estatisticamente significativas. As relaçóes entre os valores individuais indicam a importância de cada variável para o Índice. O maior coeficiente ROA é o da variável "escolaridade", com 4.027,24. Em segundo lugar e aproximadamente com metade de impacto da escolaridade aparece a variável "idade", com 2.748,93. Depois vem "renda familiar", com ROA de 1.564,67. Essas são as três variáveis com maior impacto individual (controlado pelas demais) sobre a explicaçáo do ICI. Porém, quando consideradas em conjunto no modelo o efeito individual apontado pelo ROA pode ser alterado.

A primeira estatística que identifica os efeitos individuais a partir do modelo é a Wald, que informa quanto o coeficiente $(\beta)$ da variável difere de zero, considerando a distribuiçáo do $\chi^{2}$. Na Tabela 8 , se percebe que duas variáveis diferem muito de zero: idade e escolaridade. Depois vem renda familiar. As demais variáveis apresentam Wald baixo. O nível de significância mostra que coeficientes podem ser considerados significativos e cujos resultados podem ser extrapolados da amostra para a população - no caso os brasileiros com mais de 16 anos. Três variáveis do modelo não apresentam significância estatística: renda pessoal, condição do município e região do País. Elas não terão os resultados analisados em funçáo da baixa contribuição ao modelo. 
Tabela 8 - Regressão logística entre estar ou não no Índice de Centralidade da Internet

\begin{tabular}{|c|c|c|c|c|c|c|c|}
\hline \multirow[t]{2}{*}{ Variáveis } & \multicolumn{2}{|c|}{ ROA } & \multirow[t]{2}{*}{$\boldsymbol{\beta}$} & \multirow[t]{2}{*}{ Wald } & \multirow[t]{2}{*}{ Sig. } & \multirow[t]{2}{*}{$\operatorname{Exp}(\boldsymbol{\beta})$} & \multirow[t]{2}{*}{ Chance } \\
\hline & Coef. & Sig. & & & & & \\
\hline Sexo (M) & 10,81 & 0,001 & 0,147 & 9,08 & $0,003^{*}$ & 1,159 & 15,9 \\
\hline Idade & $2.748,93$ & 0,000 & $-0,070$ & $1.204,47$ & $0,000^{* *}$ & 0,932 & $-6,8$ \\
\hline Escolaridade & $4.027,24$ & 0,000 & 0,492 & $1.235,89$ & $0,000^{* *}$ & 1,636 & 63,6 \\
\hline Renda Pessoal & 836,84 & 0,000 & 0,016 & 0,15 & 0,696 & 1,017 & \\
\hline Renda Familiar & $1.564,67$ & 0,000 & 0,478 & 177,11 & $0,000^{* *}$ & 1,613 & 61,3 \\
\hline Condição do Município & 325,08 & 0,000 & 0,017 & 0,20 & 0,650 & 1,017 & \\
\hline Porte do Município & 343,66 & 0,000 & 0,108 & 28,26 & $0,000^{* *}$ & 1,114 & 11,4 \\
\hline Região & 15,69 & 0,000 & $-0,034$ & 3,30 & 0,069 & 0,966 & \\
\hline$X^{2}$ & $6.608,59$ & 0,000 & & & & & \\
\hline Overall ROA & $4.964,78$ & & & & & & \\
\hline-2 log likelihood & $11.234,28$ & & & & & & \\
\hline Cox \& Snell $r^{2}$ & 0,386 & & & & & & \\
\hline
\end{tabular}

Fonte: Autor, a partir da Pesquisa Brasileira de Mídia 2014 (BRASIL, 2013).

A estatística mais importante do modelo é a razão de chance (oddsratio) ${ }^{14}$ de pertencer ao grupo do que estão no ICI em relação aos que não estão. No modelo apresentado aqui, a variável com a maior mudança de chance em favor do ICI é "educação". Para cada nível a mais de educação cresce em 63,6 vezes a chance de o respondente considerar a internet como central. Em segundo lugar vem a "renda familiar", com aumento de 61,3 vezes a chance de considerar a internet como central para cada ponto a mais na escala de renda mensal. Isso significa que as duas características que mais explicam a centralidade da internet para o brasileiro é escolaridade e renda familiar. Quando maior o coeficiente, mais central a internet.

Embora em níveis mais baixos, outras duas características ajudam a explicar a presença do ICI. São "sexo", com 15,9 vezes mais chances de estar no índice se mulher do que homem e "porte do município", com 11,4 vezes mais chances de estar no índice para cada mudança em favor dos municípios maiores. A única característica que reduz a chance de estar no ICI (por apresentar sinal negativo) é "idade", com efeito de $-6,8$ vezes chances de estar no índice de centralidade para cada ano a mais.

Com isso já é possível traçar um perfil do brasileiro que considera a internet como meio de comunicação importante e como fonte de informações a respeito do País. Trata-se de alguém com escolaridade, renda familiar, mais mulheres do que homens, que mora em municípios grandes e é jovem. O que falta é estabelecer o peso

${ }^{14}$ A razão de chance é calculada a partir da estatística Beta esperado $(\operatorname{Exp} \boldsymbol{\beta})$ com a seguinte fórmula: Chance $=(\operatorname{Exp} \boldsymbol{\beta}-1) \times 100$. A resposta é quanto aumenta a chance de estar no ICI para cada mudança na variável explicativa. Se o sinal for positivo significa que a mudança na variável explicativa contribui para a entrada no índice. Se for negativo, indica o contrário. 
das variáveis explicativas para a intensidade da centralidade de internet. O ICI apresenta cinco pontos, indo de centralidade muito baixa até centralidade muito alta. A regressão binária não é suficiente para indicar o peso relativo de cada categoria das variáveis independentes nas cinco categorias de centralidade da internet. Para isso a técnica usada aqui é a de análise dos Resíduos Padronizados ${ }^{15}$, que indica proporcionalmente qual a concentração de casos em cada par de categorias. Como estamos trabalhando com uma amostra representativa da população, devemos respeitar o limite crítico do Intervalo de Confiança, que para $95 \%$ localiza-se no coeficiente 1,96. Qualquer valor de Resíduos Padronizados acima de $\pm 1,96$ pode ser considerado estatisticamente significativo. Se o resíduo for significativo e positivo, isso indica que há uma concentraçáo de casos naquele par de categorias e o inverso quando o sinal é negativo. A Tabela 9 a seguir apresenta os resíduos padronizados para o ICI e todas as variáveis independentes que se mostraram significativas no teste anterior.

\footnotetext{
${ }^{15}$ A opção da análise de resíduos ao invés de outra técnica, como a regressão logística ordinal, por exemplo, deve-se ao objetivo do texto. Com análise dos resíduos é possível identificar as diferenças entre os efeitos de todas as categorias da variável independente em relação às categorias da dependente. A regressão logística ordinal tem outro objetivo, que é fornecer uma comparação dos efeitos da variação da variável dependente entre as categorias de cada variável explicativa a partir de uma categoria desta última.
} 
Tabela 9 - Resíduos Padronizados das Var. Independentes e Índice de Centralidade da Internet

\begin{tabular}{|c|c|c|c|c|c|c|}
\hline \multirow[t]{2}{*}{ VAR. } & \multirow[t]{2}{*}{ CATEGORIA } & \multicolumn{5}{|c|}{ ICI } \\
\hline & & $\begin{array}{l}\text { Muito } \\
\text { baixa }\end{array}$ & Baixa & Média & Alta & $\begin{array}{l}\text { Muito } \\
\text { alta }\end{array}$ \\
\hline \multirow{10}{*}{ 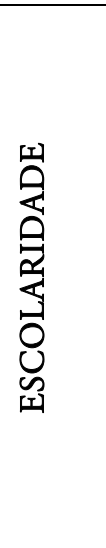 } & Analfabeto & 0,03 & 0,81 & 0,42 & $-0,42$ & $-1,06$ \\
\hline & Sabe ler/escrever mas não cursou escola & $-0,84$ & $-0,03$ & 0,28 & $-0,80$ & 1,02 \\
\hline & Primário incompleto & 2,54 & $-0,74$ & $-0,32$ & $-0,81$ & $-0,33$ \\
\hline & Primário completo & 3,67 & 2,77 & $-0,94$ & $-1,72$ & $-3,32$ \\
\hline & Ginásio incompleto & 2,93 & 1,93 & $-0,27$ & $-2,15$ & $-2,36$ \\
\hline & Ginásio completo & 2,14 & 1,78 & 0,80 & $-1,12$ & $-3,74$ \\
\hline & Colegial incompleto & $-1,18$ & $-1,21$ & 3,59 & 0,65 & $-2,92$ \\
\hline & Colegial completo & 1,21 & 1,66 & $-1,64$ & $-0,92$ & 0,14 \\
\hline & Superior incompleto & $-3,61$ & $-2,74$ & $-1,63$ & 2,47 & $\triangle 5,94$ \\
\hline & Superior completo & $-2,86$ & $-2,43$ & $-0,02$ & 1,65 & 3,58 \\
\hline \multirow{6}{*}{ 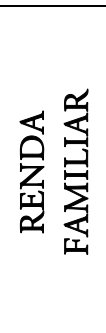 } & Até R \$ 678,00 & 2,32 & 2,63 & $-0,14$ & $-1,16$ & $-3,52$ \\
\hline & Mais de $\mathrm{R} \$ 678,00$ até $\mathrm{R} \$ 1.356,00$ & 0,10 & 2,15 & 1,45 & $-0,51$ & $-3,73$ \\
\hline & Mais de $\mathrm{R} \$ 1.356,00$ até $\mathrm{R} \$ 3.390,00$ & $-0,70$ & $-1,49$ & 0,92 & $-0,50$ & 1,32 \\
\hline & Mais de $\mathrm{R} \$ 3.390,00$ até $\mathrm{R} \$ 6.780,00$ & $-0,39$ & $-1,80$ & $-2,25$ & 1,63 & 3,75 \\
\hline & Mais de $\mathrm{R} \$ 6.780,00$ até $\mathrm{R} \$ 13.560,00$ & $-1,56$ & $-1,62$ & $-1,55$ & 1,96 & 3,37 \\
\hline & Mais de $\mathrm{R} \$ 13.560,01$ & 1,05 & $-0,96$ & $-1,32$ & $-0,76$ & 2,41 \\
\hline \multirow{2}{*}{ 学 0} & Homem & $-1,53$ & $-0,71$ & $-1,09$ & 1,45 & 2,25 \\
\hline & Mulher & 1,48 & 0,68 & 1,05 & $-1,40$ & $-2,16$ \\
\hline \multirow{7}{*}{ 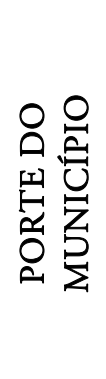 } & Até 20.000 habitantes & 0,71 & 0,73 & $-0,31$ & $-1,58$ & 0,33 \\
\hline & De 5.001 a 10.000 habitantes & $-0,01$ & $-0,14$ & $-0,13$ & 0,58 & $-0,14$ \\
\hline & De 10.001 a 20.000 habitantes & 0,60 & $-0,02$ & 1,48 & $-2,11$ & $-0,70$ \\
\hline & De 20.001 a 50.000 habitantes & 0,81 & $-1,45$ & 1,12 & $-0,15$ & $-0,53$ \\
\hline & De 50.001 a 100.000 habitantes & 0,79 & 0,78 & $-0,72$ & 0,56 & $-0,97$ \\
\hline & De 100.001 a 500.000 habitantes & 1,97 & 1,54 & 0,41 & 0,09 & $-3,83$ \\
\hline & Mais de 500.000 habitantes & $-3,32$ & $-1,09$ & $-1,34$ & 0,94 & 4,87 \\
\hline \multirow{4}{*}{ 占 } & 16 e 17 anos & $-3,79$ & $-1,07$ & 0,76 & 2,42 & 1,37 \\
\hline & 18 a 34 anos & $-3,77$ & $-0,01$ & 0,53 & $-0,16$ & 2,63 \\
\hline & 35 a 54 anos & 6,22 & 0,32 & $-0,56$ & $-0,73$ & $-4,25$ \\
\hline & 55 e mais anos & 4,40 & 0,87 & $-1,72$ & $-1,25$ & $-1,37$ \\
\hline
\end{tabular}

Fonte: Autor, a partir da Pesquisa Brasileira de Mídia 2014 (BRASIL, 2013). 
Os resíduos reforçam os achados da regressão logística. As distribuições mais consistentes localizam-se nas variáveis "escolaridade" e "renda familiar". Na primeira variável, os resíduos significativos e positivos para a categoria Centralidade Muito Baixa concentram-se nos níveis de escolaridade baixa. Já a Centralidade Muito Alta apresenta resíduos positivos e significativos para pessoas com escolaridade superior. Para a variável "Renda Familiar" percebe-se a mesma tendência. Os resíduos padronizados positivos das categorias de centralidade muito baixa e baixa estáo nas faixas de renda familiar de até dois salários mínimos mensais. Já os resíduos positivos e significativos para a categoria centralidade muito alta concentram-se nos grupos de renda familiar acima de cinco salários mínimos.

Os resíduos da variável "sexo" indicam uma inversão na intensidade de uso em relação ao número de usuários. De acordo com a regressão logística, há mais chances de termos mulheres citando a centralidade da internet do que homens. No entanto, os resíduos mostraram que entre os homens que apontam centralidade da internet, há uma concentração na categoria "muito alta", enquanto as mulheres distribuem-se nas categorias de menor intensidade. A variável "porte do município" também não apresenta tendência geral. Há uma concentração estatisticamente significativa de resíduos positivos na categoria "centralidade muito alta" em municípios com mais de 500 mil habitantes. Porém, abaixo desse número de habitantes náo é possível indicar uma tendência.

Por fim, a última variável analisada e única que apresentou sinal invertido na regressão logística é a "idade" do respondente. Como se pode perceber nos resíduos padronizados, as relaçôes mais fortes são com a categoria centralidade "muito baixa", com resíduos positivos para pessoas com mais de 34 anos de idade. Já as categorias centralidade alta e muito alta apresentam resíduos positivos e significativos para usuários entre 16 e 34 anos de idade.

\section{Conclusões}

Para concluir, as análises realizadas aqui nos permitem afirmar que o perfil do usuário de internet no Brasil a partir dos dados da pesquisa de mídia de 2013 é jovem, entre 16 e 35 anos, tem escolaridade superior incompleta ou completa, renda familiar acima de cinco salários mínimos mensais, tende a se concentrar em grandes municípios e entre os usuários mais intensivos (de maior centralidade) há uma tendência de encontrar mais homens do que mulheres.

Para se chegar a essas conclusóes, os principais achados da pesquisa foram que no Brasil quase $70 \%$ das pessoas com mais de 16 anos diz usar a internet pelo menos como um dos três principais meios de comunicaçáo. No entanto, o percentual de 
brasileiros que diz que a internet é a primeira ou segunda fonte de informaçóes cai para cerca de $40 \%$. Isso indica que embora seja um veículo de comunicação de massa, não necessariamente as pessoas buscam informaçóes enquanto navegam na rede mundial. A média é de cerca de 3 horas de navegação por dia, entre os que dizem usar a internet como meio de comunicação. No que diz respeito ao tipo de relaçáo entre usuário e internet, mais da metade diz confiar poucas vezes nos conteúdos que recebe de blogs, sites e redes sociais. Em termos de confiança do usuário a internet segue o padrão dos meios eletrônicos tradicionais (TV e rádio), ficando bem abaixo da confiança declarada em meios impressos, principalmente jornais diários e revistas semanais.

O processo de construção do ICI a partir das variáveis iniciais mostrou não haver consistência entre volume de uso e confiança nos conteúdos. Assim como a relação entre dizer usar e buscar informaçôes na internet com tempo de navegação diária também não se mostrou forte o suficiente para manter as três variáveis no índice. Por fim, em função das recomendaçôes técnicas de níveis de confiabilidade, optou-se por manter no índice apenas as respostas às baterias de questóes sobre o uso da internet como meio de comunicação e sobre a internet como fonte de informaçóes sobre o Brasil. O resultado é o que pode ser visto no Gráfico 3 a seguir, que reproduz as redes apresentadas no início do texto (Gráfico 1), porém, com as características socioeconômicas para os grupos aos quais a internet não apresenta nenhuma ou apresenta alguma centralidade. 
Gráfico 3 - Características socioeconômicas dos usuários dos meios de comunicação (ICI)

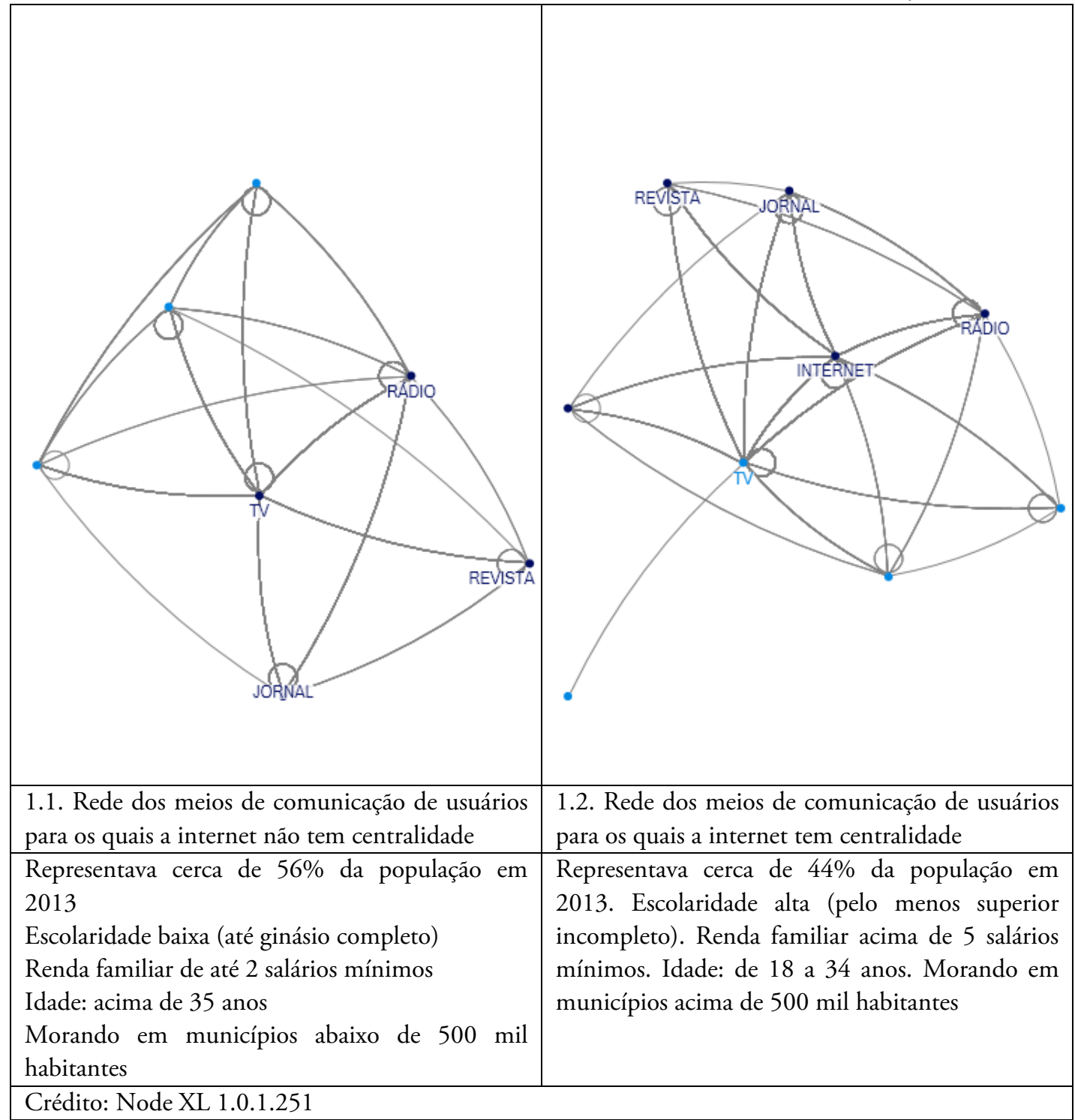

Fonte: Autor, a partir da Pesquisa Brasileira de Mídia 2014 (BRASIL, 2013).

Respondentes classificados em algum grau de centralidade do uso de internet têm alta escolaridade, renda familiar acima de cinco salários mínimos, não mais que 34 anos e vivem em grandes cidades ou metrópoles. A rede de meios usados por eles é mais densa, ou seja, tendem a citar outros meios que não a internet, porém, os meios mais integrados à internet são rádio, revistas e jornais. A TV integra um segundo cluster e passa a ser citada por aqueles que não dizem usar nenhum dos outros meios 
tradicionais. Já para os que não dão relevância à internet, a escolaridade tende a ser baixa, a renda familiar não passa de dois salários mínimos a idade é superior a 35 anos e moram em municípios com até 500 mil habitantes. Para eles, a TV é central e relaciona-se com os demais meios tradicionais (rádio, jornal e revistas), deixando em outro cluster as outras formas de comunicaçáo. Para os respondentes da pesquisa, a internet, quando se torna central substitui principalmente o uso da TV, mas não os demais meios. Em boa medida isso é explicado pela forte centralização da TV para o brasileiro ainda hoje - três em cada quatro brasileiros dizem que a TV é o meio que comunicação que mais usa. Então, quando a internet passa a ter centralidade, a TV é quem mais perde, pois ela era o principal meio até entấo.

A constatação de que os usuários com maior centralidade de uso de internet são os que têm maior escolaridade (superior) e renda familiar acima de cinco salários mínimos mensais, além de tenderem a ser mais jovens, deve ser considerado como ponto de partida para futuras pesquisas. Com essa caracterização será possível "calibrar" melhor as explicaçóes sobre o uso da internet para debate ou para deliberação política. Ou então será possível identificar os desvios nas explicaçóes sobre os efeitos das campanhas políticas online. Por que algumas campanhas e redes de interação apresentam resultados superiores a outras? A resposta não está necessariamente no meio de comunicação, mas sim na relação entre meio, conteúdo e perfil do usuário. Temas que mobilizam principalmente cidadáos de baixa escolaridade, baixa renda e maior idade tendem a não passar pelos canais de comunicação da internet ou a ter menos importância neles. Isso porque esse não é o perfil do usuário intensivo, aquele para o qual a internet apresenta alta centralidade nas formas de comunicação cotidiana.

Emerson Urizzi Cervi é Professor do Departamento de Ciência Política e Sociologia, do Programa de Pós-Graduação em Ciência Política e do Programa de Pós-Graduação em Comunicação da Universidade Federal do Paraná. É Doutor em Ciência Política. Email: ecervi7@gmail.com.

\section{Referências}

BRASIL. Presidência da República. Secretaria de Comunicação Social. Pesquisa Brasilia de Midia 2014: hábitos de consumo de mídia pela população brasileira. Brasília: Secom, 2013. 
BUCY, Erik; GREGSON, Kimberly. Media participation: A legitimizing mechanism of mass democracy. New Media e Society, v. 3, n. 3, p. 357-380, 2000.

BUNCHAFT, Guenia; KELLNER, Sheilah Ribno de Oliveira. Estatística Sem Mistérios. Editora Vozes: Petrópolis (RJ), 1999.

CARMINES, Edward G e ZELLER, Richard A. Reliability and validity assessment. Sage University Paper: California, USA, 1979.

CASTELLS, Manuel. El Poder en La Sociedad Red. In: CASTELLS. Comunicación y Poder. Madrid: Alianza Editorial, 2009.

CERVI, Emerson U. Mundo virtual, poder real: mesmo sob novas condiçóes a alocação de poder político não necessariamente muda. Revista Cadernos Adenauer. v. 3, p.11-31, 2012.

CORTINA, José M. What is coeficient alfa? na explanation of theory and applications. Journal of applied psychology, v. 78, n. 1, p. 98-104, 1993.

CRONBACH, Lee J. Coeficient alfa and the internal structures of tests. Psychometrika. n. 16, p. 297343, 1951.

DAHLGREN, Peter; SPARKS, Colin. Communication and Citizenship - Journalism and the Public Sphere in the new media age. London: Routledge, 1993.

ECHEGARAY, Fabian. Dimensões da Cibercultura no Brasil. Revista Opinião Pública, v. 9, n. 2, p. 20-45, 2002.

ELLIOT, Mark. Binary Logistic Regression. Teaching Paper. v. 20, 2008.

FUENTES, Josué G. Web 2.0: visão geral sobre a comunicação baseada na web entre partidos políticos latino-americanos. Revista Cadernos Adenauer, v.3, 2012.

IASUILATIS, Silvia. Internet e campanhas eleitorais: experiências interativas nas cibercampanhas presidenciais do cone sul. 2012. Tese Doutorado em Ciência Política do Programa de PósGraduação em Ciência Política, Universidade Federal de São Carlos, São Carlos, 2012.

LAZER, David et al. The Coevolution of Networks and Political Attitudes. Political Communication. n. 27, p. 248-274, 2010.

LOMBORG, Stine. Becoming a 'tweep': networks of affiliation and relational pressures on twitter. OBS* Journal. v.6. n. 1, p. 111-127, 2012.

MAIA, Rousiley Celi Moreira. Internet e esfera civil: Limites e alcances da participação política. Porto Alegre: Editora Sulina, 2011.

MARQUES, Francisco Paulo Jamil Almeida (Org.). Internet e participaçáo politica no Brasil. Porto Alegre: Sulina, 2012.

MCKEEVER, David; RAPPORT, Mike. Trazendo a sociedade de volta: 1848 e 2011. Revista Cadernos Adenauer, v. 3, 2012.

PAPACHARISSI, Zizi. Democracy online: civility, politeness, and the democratic potential of online political discussion groups. New Media and Society, v. 6, n. 2, p. 259-283, 2004.

PEREIRA, Rafael E. M. et al. Quantificando a centralidade urbana: uma proposta de índice simples e comparação internacional. Ipea, Textos Para Discussão, n. 1675, p. 1-40, nov. 2011.

POGREBINSCHI, T. The Squared Circle of Participatory Democracy: Scaling-up Deliberation to the National Level. APSA, Annual Meeting Paper, 2012.

SMITH, Marc A. et al. Analyzing (Social Media) network with NodeXL., USA: CeT'09 Review, Pennsylvania, n. 25-27, 2009. 
96 | Emerson Urizzi Cervi

TEDESCO, John C. Changing the Channel: Use of the internet for communicating about politics. In KAID, Lynda Lee. Handbook of Political Communication Research. Florida: Lawrence Erlbaum Associates, 2004.

Texto recebido em 14 de outubro de 2015. Aprovado em 10 de novembro de 2015. 